\title{
Report on services and training from the Executive Committee of the Substance Misuse Section
}

The recognition of a distinct body of knowledge, skills and experience in the creation of a distinct section of the College warrants a report on services and training in the field. A working group of the Executive Committee makes the following recommendations which relate to alcohol and other drugs.

\section{Regional services}

Health Districts should plan at least for the fulltime appointment of a consultant or consultants in general psychiatry with identified sessions. The services may consist of a central provision funded by the regional health authority or of subregional units also so funded. The regional (or subregional) services should be sufficiently staffed to provide support and expertise to district services and to non-psychiatric facilities, together with training and research.

\section{District services}

Health districts should plan for the appointment of a consultant or consultants in general psychiatry with identified consultant sessions. An average district would provide a minimum of four consultant sessions for this purpose, i.e. one session per 50,000 population. The sessions may be held by one consultant or split between consultants with respect to alcohol and other drugs.

Out-patient, day patient and in-patient facilities are required, with support from other disciplines, especially nursing (including community psychiatric nursing), psychology and social work.

3. In-patient provision

In-patient therapy involves detoxification combined with counselling and with the initiation of long-term treatment arrangements. Regional units contain sufficient patients to permit a group ethos. The designated district consultants should have access to beds which will be usually, although not necessarily, located within their own district. Based on models of good practice it is considered that the substance misuse services should possess a range of four to seven hospital beds per 50 thousand population. The number chosen depends on the extent of substance misuse within the population and on the availability of alternative beds in hostels.

\section{Local representation}

The regional representative of the Section or the specialty tutor should be a member of regional committees that exercise education, manpower or other advisory functions relevant to psychiatry.

The district consultant with a special responsibility for substance misuse should be a member of relevant local committees.

\section{Relations with other services}

Time should be allocated for consultants in the regional and district services to encourage initiatives from and cooperate with medical nonmedical personnel. Among the persons with whom liaison is required are members of primary health care teams, physicians, social workers, probation officers, health promotion officers and the staff of voluntary agencies.

\section{Senior registrar training and appointment of} consultants

The College could implement the intentions of the Report on Senior Registrar Training in Alcoholism and Drug Dependence (Bulletin, January $1984,8,5-6$ ). A prospective consultant for a post with special responsibility for substance misuse should spend a minimum of 12 months in wholetime approved training as a senior registrar in the sub-specialty. Senior registrars who intend to become consultants devoting the majority of time to alcohol or drug dependence or to both should spend at least 18 months training in alcoholism and drug dependence.

\section{Registrar, senior house officer and general} practitioner training

It is highly desirable that junior psychiatric trainees receive a minimum of three months whole-time or six months part-time training in substance misuse from a consultant who has responsibility for district or regional services. It is desirable that junior trainees in psychiatry have the opportunity of six months full-time experience of substance misuse in an approved post.

Trainees for general practice should obtain some experience with substance misuse services.

\section{Approved by the Court of Electors}

June 1988 